dynamical behaviour, especially as regards detail on a slightly smaller scale than that of the patterns which the two-parameter model reproduces reasonably well. Mr. Sawyer was only able to mention some recerit work of his on computing the intensity of 'fronts', which may go some way towards taking these factors into account.

To indicate that oceanographers are keenly interested in problems closely akin to the main topics, Mr. H. Charnock showed a film of experiments by von Arx with a rotating bowl of fluid. Raised boundaries on the concave inner side of the bowl represent the continental coast-lines, the fluid itself the oceans. The fluid is set in motion relative to the rotating bowl by jets of air representing the drag due to the Westerly and Trade winds. It was noticeable how faithfully the broad outline of the main ocean currents is reproduced in the model. The experiment was designed to test the well-known theory due to Stommel and Munk of the wind-driven ocean circulations.

During an interval for discussion, Mr. T. V. Davies described some theoretical work he had done relating to the experiments made by Hide. He gave a formula for the stability of the wave-like pattern occurring at relatively high rotation-rates in terms of the Richardson number and what has been called the Rossby number (the ratio of the relative motion of the fluid to the motion of the cylinders). He also gave a formula, based on earlier work by Lorentz, relating these two parameters. Unfortunately there was too little time to do justice to this interesting, important but rather complicated subject. It is to be hoped that Mr. Davies will be given an opportunity to present his work in detail and that more time will be allotted for its discussion.

The last speaker was Dr. E. T. Eady, who discussed the properties of 'turbulent' transfer in rotating convecting fluids, with applications to the theory of the general circulation of the atmosphere and to the theory of the earth's main magnetic field. His general theme was that the transfer properties of turbulence are not always of a diffusive nature, as is assumed when effective eddy-transfer coefficients are postulated, but are sometimes anti-diffusive in character to the extent that organized patterns may be built up as a result of the transfer. Moreover, the transfer properties depend on the nature of the process which maintains the turbulence against dissipative forces, and the only reliable guide is a theory of the mechanism. Dr. Eady illustrated these points by considering some aspects of the so-called 'general circulation' of the atmosphere. 'The largescale 'eddies' (corresponding to depressions and anticyclones) are a form of convection modified by rotation to such an extent that the heat transfer associated with their continued regeneration is in a slanting direction from a heat source in low latitudes to a radiative sink at higher levels in high latitudes. As a secondary feature these eddies also 'transfer' angular momentum. The nature of this transfer, which results in the maintenance of the Westerlies and Trades against surface friction, is readily understood in terms of the average structure which theory shows these eddies ought to have (and which they are observed to have); but it cannot be understood in terms of any simple diffusion hypothesis, whether this be based on transfer of angular momentum or on transfer of vorticity.

Transferring his attention to the problem of convection in the earth's core, Dr. Eady pointed out that, due to the varying ellipticity of the geoids and variation in surface temperature, the innor core ought, because of the resulting horizontal density gradients, to rotate more slowly than the mantle. Observed irregular variations in the length of day are consistent with irregular free convective motion in the liquid core. He then outlined a possible natural dynamo mechanism for the maintenance of a variable main magnetic field. Supposing initially a small, approximately dipole (magnetic mode) field to exist, the gradient in rotational velocity previously deduced would wind the lines of force around the earth's axis, leading to a large electric mode field (lines of force roughly parallel to lines of latitude). Convection would draw out the electric mode field into loops. Statistically these loops would tend to set themselves most frequently so that the lines of force had the same direction as the original dipole field where this is strongest, near the inner core. Finally, because of the finite electrical resistance, the lines of force in the sides of the loops near the mantle would diffuse through, ultimately into space, leading to an increase in the strength of the initial dipole which might be sufficient to maintain it against natural decay.

In the discussion, Dr. J. M. Stagg asked how the secular variations could be due to convection in the core since some of the foci of variation are close together. Prof. H. Bondi agreed, pointing out that spherical harmonics of high order decrease rapidly with radial distance. However, Dr. F. J. Lowes said that actual calculation shows that the secular variation is consistent with dipoles in the core of only moderately large strength. Prof. Bondi wondered whether all dynamo theories are invalidated by either Cowling's theorem or a theorem of Batchelor on homogeneous turbulence. Dr. Eady replied that Cowling's theorem does not apply if the field is maintained by turbulent motion; also, the theorom of Batchelor does not apply to the theory he had put forward because homogeneous turbulence has only diffusive properties whereas the mechanism he envisaged was anti-diffusive in one important respect.

E. T. EADY

\section{BUFFALO HUNTING IN ARNHEM LAND}

$\mathrm{T}$ is difficult to believe that the docile, domesticated water-buffaloes of the East Indies are the same species as the fierce and dangerous buffaloes hunted in Western Arnhem Land in Australia (Austral. Mus. Mag., 11, No. 8). Yet the water-buffalo forms an interesting link between. Australia, Indonesia and India, and was a profitable experiment in the colonizing of northern Australia in the early nineteenth century. Three buffaloes were imported from Timor into the Melville Island settlement in 1825, and others were introduced over the next twenty years. Once ashore, they became too wild and dangerous to domesticate.

They were well established on Melville Island and on the Cobourg Peninsula on the mainland by 1849 . With no natural enemies except the dingo, and as they were remarkably resistant to disease, the animals gradually spread southward into a natural and ideal environment in the vast swamps and grasslands of the Mary, Adelaide and Alligator Rivers and westward to the Darwin coast. Stray bulls have wandered into Victoria Downs, some five hundred 
miles to the south, and as far east as Caledon Bay on the Gulf of Carpentaria. The increase was so rapid that by 1885 it was estimated that there were six thousand buffaloes on Melville Island and about sixty thousand on the mainland.

The water or Asiatic buffalo, Bubalis buffelus, is a powerful animal, more than five feet high and almost ten feet long. It is heavily built, has short powerful legs with white fetlocks and large hoofs, a short tail and brown hair on an ashy-grey to blackish hide. The immense, hollow and sharply pointed horns may be crescentic in shape or develop into several spirals. The wild herds do not roam far afield from where they were born, their spread through the country in small herds being gradual as their numbers increase. They stay near water, in which they will stand for hours side by side, with only the wide muzzles and horns of their long heads uncovered. The bulls fight for control of a herd of cows in the autumn mating season, and old bulls unable any longer to hold their own with their younger rivals become wandering outcasts of an extremely dangerous nature. A cow bears one calf each year. The bulls will charge a foe threatening the herd.

This buffalo is a native of north-eastern India, where wild ones cause considerable damage to crops. It has a reputation for being the most dangerous animal after the tiger, and is always shot by hunters from an elephant. Hunting began in Australia in 1885, but after 1905 the great and uncontrolled slaughter of the beasts soon depleted the herds perilously and the Government took steps to save them. Permits are now issued for hunters to operate in a defined area. They are allowed to shoot a quota of bulls, but no cows. In recent years between six and eight thousand buffalo skins have been marketed annually for heavy machinery belts and similar uses, at an average price of between $£ 5$ and $£ 6$ per skin.

The hunting of buffaloes in western Arnhem Land is a dangerous and strenuous job, carried out in the dry season. It demands great horsemanship, skilful shooting and endurance above the ordinary. In the past, the ruthless depletion of the herds, the employ. ment of natives who get little reward but disrupted lives, added to its undesirable nature; these defects have now been rectified. As the dingo is the only natural enemy of the buffalo in Australia, the shooting of a specific number each year is essential or the herds would expand beyond the country's resources to sustain them.

\section{MICROWAVE AMPLIFICATION BY STIMULATED EMISSION OF RADIATION}

NEW instrument called the 'maser' (microwave
amplification by stimulated emission of radia-
tion) has been invented by Prof. C. H. 'Townes, of the
Physics Department, Columbia University, for which
the claim is made that it enables time to be measured
with an accuracy of one part in $10^{11}$. The 'clock'
used is an ammonia molecule which radiates an
electric dipole spectrum as a set of lines of about $6 \mathrm{~mm}$.
wave-length and, as used in the instrument, maintains
its frequency to the above order of magnitude. This
would be sufficient to enable it to measure variation
in the rate of rotation of the earth.
According to the details issued by Columbia
University, the instrument consists of a molecular beam of ammonia molecules which are excited in an electric field and then pass into a tuned cavityresonator, where they induce each other to radiate by negative absorption (in effect, giving a form of chain reaction). In this way, all factors causing broadening or displacement of the line emitted are reduced to a minimum. It seems that the method of use is to extract by means of wave-guides the radiation emitted by two 'masers', tuned to different but adjacent frequencies by the ammonia spectrum. When mixed, the beat frequency can then be counted electronically. 'The 'maser' is also claimed by its inventor to be very effective as an amplifier. The signal is fed into the resonant cavity, and a molecular beam, too weak to cause a complete chainreaction, is introduced. The signal controls the rate of emission of the radiation, again by negative absorption, and, it is stated, the system is almost completely free from noise. Thus it would be very useful for amplification at millimetre wave-lengths. A limitation, however, would appear to be that the device is scarcely tunable. The only frequencies available are the half-dozen or so lines of the ammonia molecule, all in the $6-\mathrm{mm}$. region of the spectrum, and the lines of other chemical compounds. It is not stated what sort of a total band may be expected ultimately to be covered by the frequencies of various compounds.

The 'maser' is not the only time-measuring device using microwave spectra of molecules. The alternative method is to use an absorption technique, tuning a conventional oscillator on to exactly the molecular frequency. But Prof. Townes claims that this method is considerably less accurate. As at present built, the 'maser' is a fairly large device, a few cubic feet in volume, but Prof. Townes suggests that this can be considerably reduced. He proposes that, apart from being used as an accurate clock for experimental work on the earth's rotation period, it might also serve as a frequency standard for radio frequencies generally. This would certainly give greater accuracy than the usual quartz crystal, but it is doubtful if this is required, and the method would be less convenient to use, except perhaps in the region of centimetre waves.

\section{MYXOMATOSIS OF RABBITS}

$\mathrm{T}$ HE second report of the Advisory Committee on Myxomatosis* follows fairly soon after the first report (see Nature, 173, 856 ; 1954) and records that this disease, which appeared in Kent, Sussex, Essex and Suffolk in 1953, had, by the end of 1954, spread to every county in Great Britain except Selkirk. It had appeared as far north as the Orkneys, but its spread was most marked in southern England and in Wales, only isolated outbreaks occurring in northern England and Scotland. A map issued with the report shows the extent of the distribution of the disease at the end of 1954. In Europe the disease exists in France, where it has resulted in the virtual disappearance of rabbits over large areas, and in Belgium, Luxembourg and elsewhere. It also exists in Ireland.

In view of reports that symptoms resembling those of myxomatosis have been reported in animals other

* Ministry of Agriculture and Fisheries-Department of Agriculture for Scotland. Myxomatosis: Second Report of the Advisory Com-
mittee on Myxomatosis. Pp. ii $+6+1$ map. (London: H.M.S.O., 1955.) 1s. net. 